\title{
Analysis of factors affecting highway route selection and reasonable design
}

\author{
Yongcheng He \\ Highway Institute of Yunnan Jiaotong College, Yunnan, China, 650500
}

Keywords: highway; route selection; factor analysis; rational design

Abstract: Expressway is an important hub that connects the city to guarantee the basic smooth and promotes the economic development. In the construction of highways, the choice of route is very important. When designing the expressway route, we must first determine the basic direction of the route, and then the optimal choice of the route plan, and finally determine the specific limit. Therefore, it is a very complicated process for highway options, which involves many factors such as social economic factors and natural environment. Based on this situation, this paper discusses the influencing factors and rational design of highway route selection, and provides reference for the construction of expressway, so as to better promote the construction of basic traffic facilities and provide assistance for economic development.

\section{Introduction}

As the city continues to develop, the highway becomes a major gateway between the city and the city. When constructing a highway, there are many factors to be considered in the specific route selection, such as political factors, economic factors and national defense factors. From a basic point of view, the principle of the route selection of the expressway is mainly the short-term direction connection. Under this design pattern, the problems involved are also more complex content, the water conservancy situation of farmland, and some important towns and industrial construction. Generally speaking, when selecting the expressway route, it is necessary to avoid occupying too much land, causing too much demolition, and minimizing its interference with the surrounding environment, so that the construction and design of the expressway is reasonable and optimized can promote the sound development of the economy and society ${ }^{[1]}$.

\section{The main influencing factors of highway route plan selection}

For the route selection of expressways, it is a key link in the overall road design, which will be affected by various construction areas and socio-economic environment. In addition, road capacity landscape, geological conditions and so on are to be considered. In general, when selecting the route selection of expressways, the main factors affecting the choice of highway route plan are the overall economic development plan, the impact of regional road network planning, the impact of high-voltage line corridors and their power grid planning, and the impact of landscape and environmental design. 


\subsection{Economic development master plan}

The primary consideration of expressway route selection is that it is in line with the overall planning goal of urban economic development, and it can effectively organize and dredge urban transit traffic and urban and external traffic connection, speed up the economic development of cities, promote the urbanization process, and promote the social and economic development of cities and surrounding areas.

\subsection{Impact of regional road network planning}

Highway line selection response area present situation and the future of railway, highway and existing main distribution network planning and detailed investigation, coordinate the relationship with the railway, highway departments, railway station and national highway in the net, net width, accessory line, concealed structure, line on both sides of the building safe distance and meet the requirements of the program plan, and ensure the normal operation of the existing highway network construction period ${ }^{[3]}$.

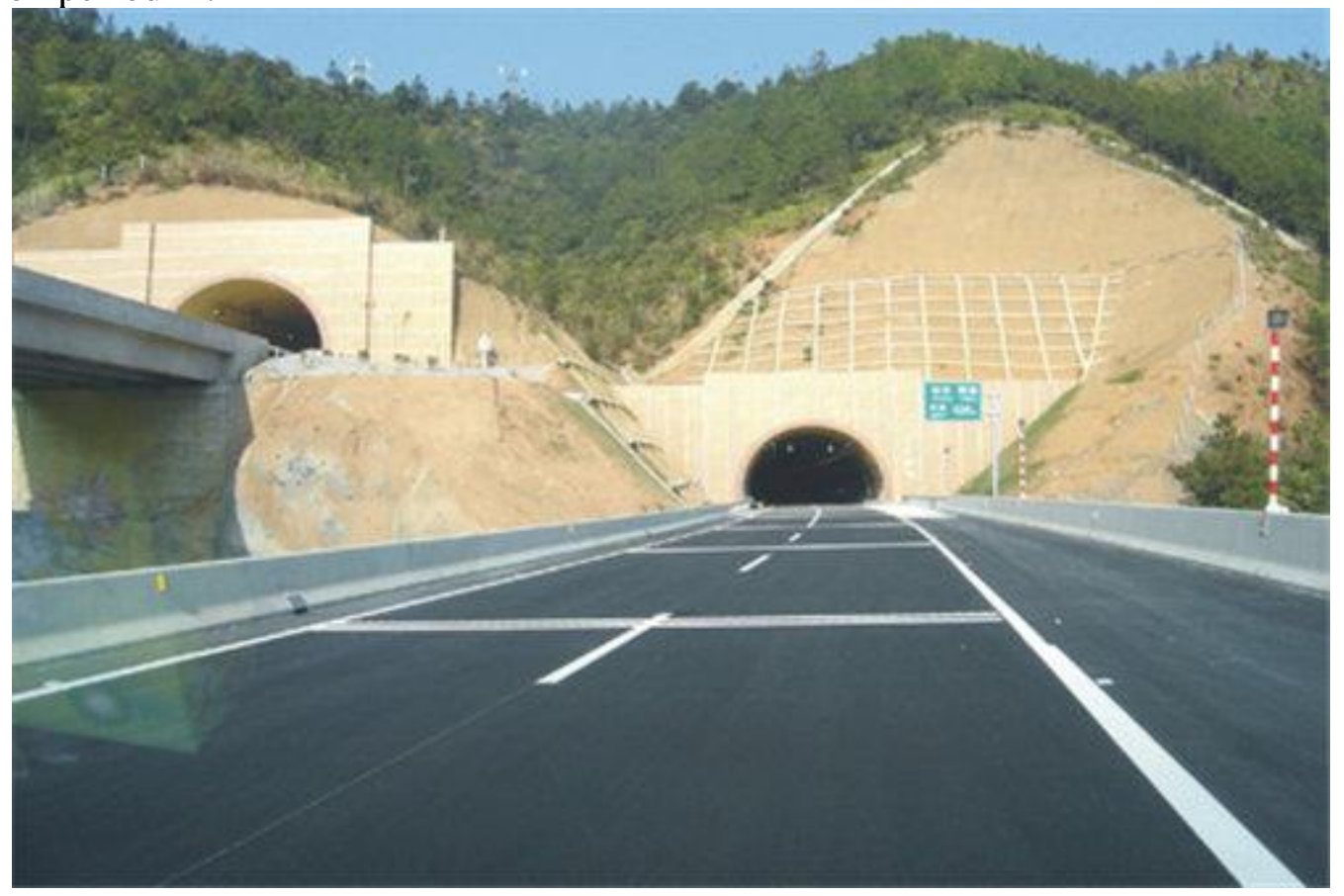

Figure 1 Highway route selection design

\subsection{Impact of high-voltage line corridors and their power grid planning}

In the process of highway line selection, it often crosses with the grid in a certain area, which inevitably leads to multiple crossings of the route. How to coordinate the relationship between the highway line shape and the high-voltage transmission line corridor and power plant planning has a great influence on the line position. When selecting the line position, the high-voltage line corridor should be avoided as much as possible. The tower can be demolished without demolition. At the same time, it should be coordinated with the power plant. The high-voltage line corridor planning and the highway line orientation should be combined with each other to adjust the mutual interference. 


\subsection{Landscape and environmental design impact}

Highway construction will have certain impact on the social and natural environment along the route. How to protect the environment and carry out landscape design is an important part of environmental impact assessment of highway construction. In the project survey and design stage, the natural geographical conditions of the construction area (topography, stratum lithology, regional geological structure and earthquake, water level engineering geological conditions, meteorology, water system and unfavorable geological conditions), social and cultural environment, and roadscape landscape requirements should be combined. Focus on research and demonstration of roadbed protection forms, roadside beautification greening schemes, special landscapes and scenic spots design, combining engineering protection with ecological protection, drawing on the successful experience of existing projects, doing landscape greening design, and preventing soil erosion. Construction of landscape roads, environmental protection roads and ecological roads ${ }^{[4]}$.

\section{Research on line selection in expressway design}

Line selection is an important part of highway survey design. It includes the selection of the basic direction of the route, the comparison of the route plan, and the layout of the route to the specific process of determining the line position. It faces a very complicated natural environment and socio-economic conditions. It needs to consider various factors in a comprehensive way. It must be economically reasonable, technically feasible, and able to meet the requirements of road use. To this end, the line selection design work must be analyzed and compared in stages and steps to determine the most reasonable route. At present, the line selection research in highway design mainly focuses on the flat linear design and the vertical linear design.

\subsection{Plane linear design}

When driving on a parallel curve, the vehicle mainly exhibits two modes of radial rotation and translation. When the vehicle is driving on a flat curve, it is necessary to maintain a smooth transition as much as possible. If the vehicle suddenly changes in the curve on the highway, it will affect the translation and normal rotation of the vehicle, and may also cause traffic accidents. It can be seen that when designing the plane route of the expressway, it should be limited by the minimum radius of curvature in the flat curve design. In addition, there should be a transition of the transition curve connecting the plane curve.

\subsection{Longitudinal linear design}

There are many factors affecting driving safety and vertical curve, such as slope length, driving line of sight and slope change. When designing the route of the expressway, it is necessary to consider all the above factors. The normal rotation and translation of the vehicle is the rotation mechanism of the vehicle on the vertical curve. When the vehicle passes the longitudinal ramp, the vehicle speed is accumulated, which increases the probability of a safety accident. The requirements for the minimum radius of the minimum length of the vertical curve at different speeds are shown in Table 2. If the design speed is constant, the vertical curve radius and length of the highway are lower than the relevant limit. This will make the driver unable to use the driving route. Under the influence of line of sight, the probability of a safety accident will increase ${ }^{[5]}$. 
Table 2 Minimum length and radius of vertical curves at different design speeds

\begin{tabular}{c|c|c|c|c}
\hline \multicolumn{2}{c|}{ Design speed $(\mathrm{Km} / \mathrm{h})$} & 120 & 100 & 80 \\
\hline \multirow{2}{*}{$\begin{array}{c}\text { Concave } \\
\text { vertical curve } \\
\text { radius }\end{array}$} & General value & 6000 & 4500 & 3000 \\
\cline { 2 - 5 } & Limit value & 4000 & 3000 & 2000 \\
\hline $\begin{array}{c}\text { Convex } \\
\text { vertical curve } \\
\text { radius }\end{array}$ & General value & 17000 & 10000 & 4500 \\
\cline { 2 - 5 } & Limit value & 11000 & 6500 & 3000 \\
\hline $\begin{array}{c}\text { Vertical curve minimum } \\
\text { length }(\mathrm{m})\end{array}$ & 100 & 85 & 70 \\
\hline
\end{tabular}

In addition, for the traffic safety of highways, the slope length and slope of the route will also have a certain degree of impact on safety. Once the slope needs to be converted multiple times, it will affect the stability of the driving, thus enabling the driver to generate Driving the illusion. At the same time, if a single slope is used in the design, the driver will be prone to fatigue driving. Therefore, the design of the slope must be smoothly combined. Under normal circumstances, when the highway slope design work is carried out, it can be set to $-2 \sim 3 \%$, thus effectively preventing the wrong estimation of the speed caused by the slope.

\section{Conclusions}

In summary, the expressway is an important link between the city and the city. Without the expressway, the economic development will be severely constrained. Under such circumstances, it is very necessary to promote the construction of the expressway. In the construction of expressway, the selection of line is a very important content, which involves many factors, which is very important to the overall impact. The analysis and research on the specific influencing factors and the discussion of reasonable design are beneficial to the construction and development of expressways.

\section{References}

[1] Yang Yonggang. Influencing Factors and Rational Design of Expressway Route Selection [J]. Industry B, 2015(1):158-158.

[2] Xiao Jun. Research on Route Selection in Highway Design [J]. Low Carbon World, 2017(13): 197-198.

[3] Chen Yanjun. Influencing factors and rational design of expressway line selection [J]. Industry c: 00082-00082.

[4] Liu Zhimin, Li Zhenzhen. Influencing Factors and Rational Design of Expressway Route Selection [J]. Commodity \& Quality, 2015(22).

[5] Yu Caibo. Influencing Factors and Reasonable Design of Expressway Route Selection [J]. Architecture, 2012(6):87-88. 